\title{
Dual-curable stereolithography resins for superior thermomechanical properties
}

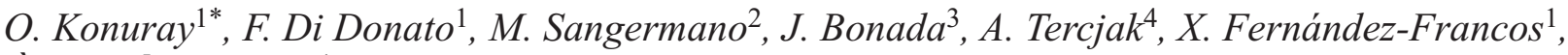 \\ A. Serra ${ }^{5}$ X. Ramis ${ }^{1}$ \\ ${ }^{1}$ Thermodynamics Laboratory, ETSEIB. Universitat Politècnica de Catalunya, Avda. Diagonal 647, 08028 Barcelona, \\ Spain \\ ${ }^{2}$ Politecnico di Torino, DISAT, Corso Duca degli Abruzzi, 24, 10129 Turin, Italy \\ ${ }^{3}$ Strength of Materials and Structural Engineering, ETSEIB, Universitat Politècnica de Catalunya, Avda. Diagonal 647 , \\ 08028 Barcelona, Spain \\ ${ }^{4}$ Group 'Materials + Technologies', Polytechnic School, Department of Chemical Engineering and Environment, \\ Universidad País Vasco/Euskal Herriko Unibertsitatea, Pza. Europa 1, 20018 Donostia-San Sebastián, Spain \\ ${ }^{5}$ Department of Analytical and Organic Chemistry, Universitat Rovira i Virgili, C/Marcel·lí Domingo s/n 43007 \\ Tarragona, Spain
}

Received 16 December 2019; accepted in revised form 28 February 2020

\begin{abstract}
Stereolithography (SL) stands out as a relatively fast additive manufacturing method to produce thermoset components with high resolutions. The majority of SL resins consist of acrylate monomers which result in materials with curing-induced shrinkage problems and this, in addition to the incomplete and non-uniform conversions reached in the SL process, results in poor mechanical properties. To address this issue, a dual-curing formulation was developed by mixing an epoxy monomer into a commercial multi-acrylate SL resin: the first curing stage is acrylate free-radical photopolymerization at ambient temperature, and the second curing stage is cationic epoxy homopolymerization at higher temperatures.

The fully dual-cured materials are macroscopically homogeneous, with nanoscale domains observed by Atomic Force Microscopy (AFM), and with unimodal tan delta peaks observed in Dynamic Mechanical Analysis (DMA). The uncured material was storage stable at ambient conditions for at least 9 weeks since the epoxy part was virtually unreactive at these temperatures. With the dual-cured materials, a nearly 10-fold increase in Young's modulus was achieved over the neat acrylate resin. At the thermal curing stage, the presence of diperoxyketal thermal radical initiator to the liquid formulation facilitated the polymerization of unreacted acrylates that remained from the SL process simultaneously with epoxy homopolymerization and helped the material attain improved properties.
\end{abstract}

Keywords: thermosetting resins, stereolithography, dual-curing, epoxy

\section{Introduction}

Over the last decade, additive manufacturing (AM) has attracted attention from the polymer science community as a new and versatile polymer processing method. Despite its introduction some 30 years ago, additive manufacturing methods are only recently nearing their booming period with a plethora of challenges still lying ahead. Nevertheless, for the near future, AM is regarded as a replacement for conventional production methods [1,2]. Initially, AM was touted as an efficient prototyping tool. However, with the recent advances in polymer chemistry, it shows potential in customized manufacturing of biomedical materials [3-5], machinery parts [6], sports goods [7], and shape memory materials [8]. 
Among the numerous AM methods, stereolithography (SL) stands out as a relatively faster method that can produce parts with high resolutions. The technology is based on photopolymerizable materials such as those reviewed in earlier papers [9]. As shown in Figure 1, in a particular SL process, namely Mask Image Projection based on SL (MIP-SL) [10, 11], the stage that carries the cured part sinks in the bath until a determined depth so that liquid resin wets its surface. Next, an image of the cross-section of the part is projected onto this resin layer, and the process repeats $[6,7]$. As a result, the part is additively produced in thin layers, and resolutions down to $50 \mathrm{mi}-$ crons can be achieved [2]. In the MIP-SL process, the energy is delivered simultaneously to the irradiated area so that the manufacturing process is expedited. This is in contrast to the traditional SL process in which a single spot UV-laser is used to scan the area [11].

The majority of SL resins have acrylate chemistry, which results in brittle final materials with polymerization-induced shrinkage problems unless formulated using different approaches [3, 12]. Furthermore, a purely acrylate-based photocuring resin has thermal and mechanical properties that usually fall short for demanding applications. An effort has been spent in the past to improve properties by using nanofillers [13]. As a matter of fact, a two-stage curing scheme can also fight the drawbacks associated with purely acrylic resins. It is reported in the literature that epoxy-based formulations exhibit lower polymerization-induced shrinkage [14-16]. The motivation for research on an epoxy-based dual-curing SL resin can, therefore, be drawn from here. Incorporating epoxy chemistry with a dual-curing approach would also help achieve higher crosslinking densities and materials with higher glass transition temperatures $\left(T_{\mathrm{g}}\right)$ as was documented previously [17-20].

In SL printers, whereas the speed limiting factor is resin curing kinetics for parts with small details, it is resin viscosity for parts that have wide cross-sections [7]. With a dual-curing formulation, both these parameters can be tightly controlled. Measures could be taken to optimize curing schedules to reduce spatial gradients of temperature and conversion along part dimensions and in turn, minimize risks such as deformation, cracking, and delamination [21-23]. In prototyping, this is crucial for high dimensional consistency between the prototype and the actual part. In this work, a commercial SL resin preparation consisting of aliphatic acrylates and urethane acrylate oligomers was modified with a cycloaliphatic epoxy compound. The main objective of this modification was to improve the otherwise poor thermal and mechanical properties of a purely acrylic printed part. A similar approach was used by Kuang et al. [24] in which they modify a purely acrylic SL resin with epoxy. Using an anhydride curing agent, they cure the epoxy at a subsequent thermal curing step after an SL step. In contrast, the dual-curing scheme presented herein consists of photoinitiated free-radical acrylate homopolymerization, followed by cationic epoxy homopolymerization. After the second curing stage, due to the rigid polyether structure that develops, the
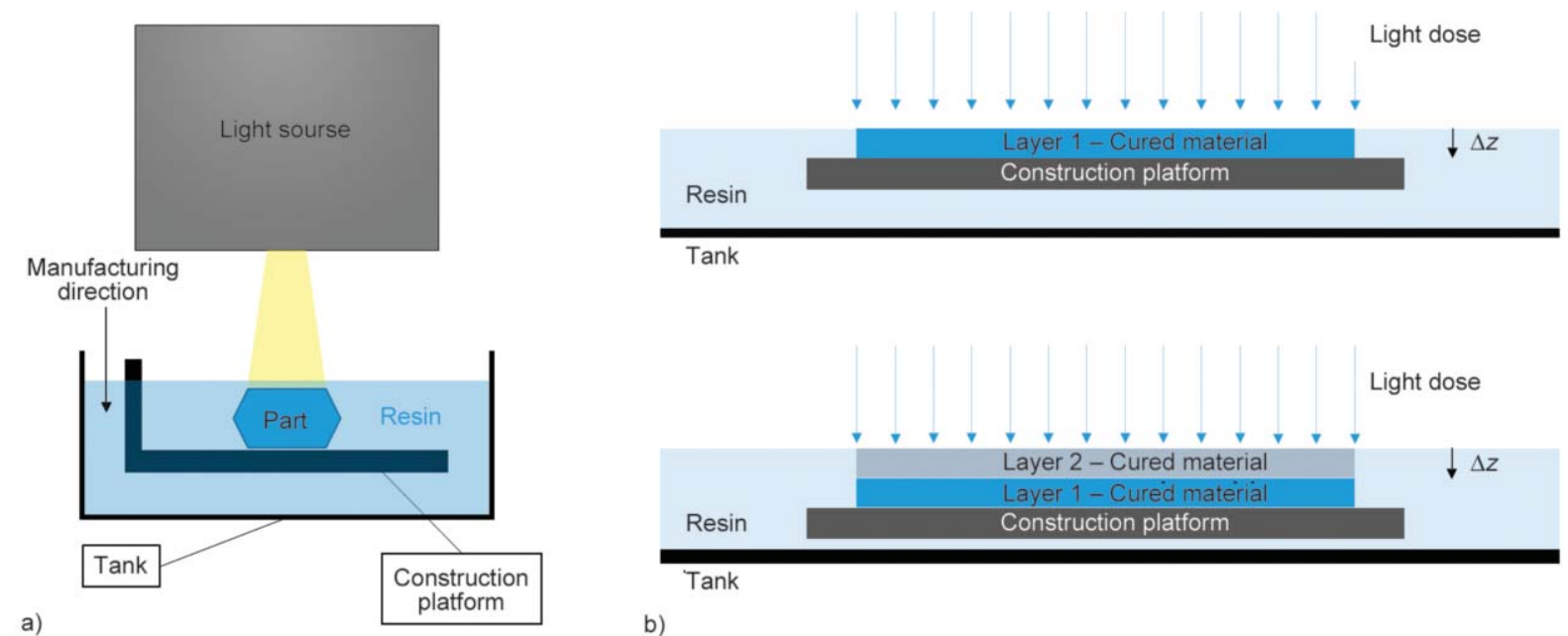

Figure 1. (a) Top-down configuration for a Mask Image Projection based on Stereolithography equipment. (b) Schematics of the manufacturing process. A mask image is projected onto the resin surface. After a certain dose of light irradiation, the first layer solidifies. For the next layer, the construction platform moves down a distance equal to the layer thickness and a new layer of liquid resin covers the surface of the previous layer and the curing process is repeated. 


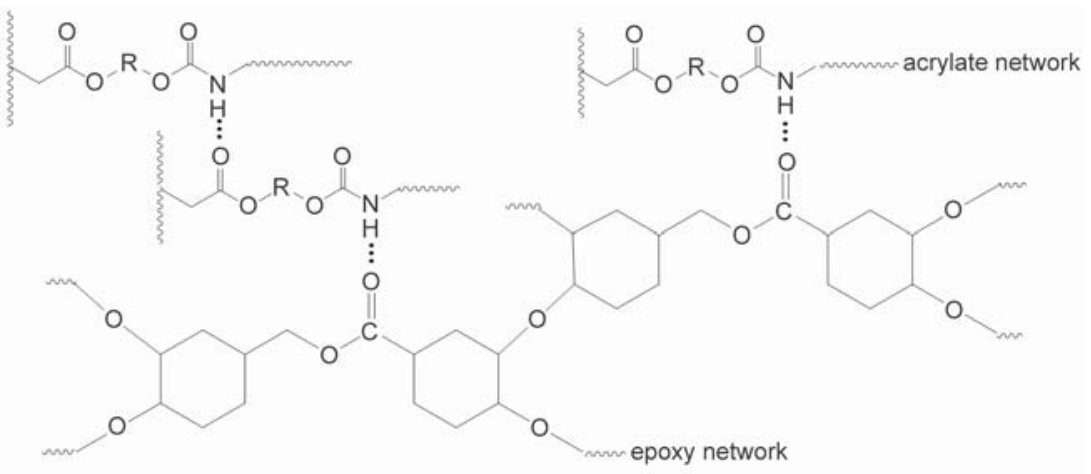

Figure 2. Possible H-bonding intereactions in the dual-network.

material attains significantly higher $T_{\mathrm{g}}$ compared to the final material produced from a neat Spot-HT resin. Moreover, one can argue that possible H-bonding interactions, as depicted in Figure 2, between carboxylic oxygens of the polyether network and the amine hydrogens of the urethane links would promote better compatibility between the two networks. One should also note the internal H-bondings within the urethane-acrylate oligomer.

A drawback of the SL process is the occurrence of conversion gradients along either dimension due to temporal differences in irradiation dosages. Taking this into account, a thermal radical initiator was added to the liquid formulation so that the acrylate monomers that remain from the SL process can polymerize at the subsequent thermal post-curing stage simultaneously with epoxy homopolymerization, and that the final material can attain its ultimate thermomechanical properties.

\section{Experimental}

The SL resin preparation, with trade name Spot-HT (Spot-A Materials, Barcelona, Spain), having a viscosity of $350 \mathrm{mPa} \cdot \mathrm{s}$, is a mixture of aliphatic and urethane acrylates and a photoinitiator which has an absorption range in the UV-visible region of the spectrum (exact formulation not disclosed by the supplier). A cycloaliphatic epoxy resin 3,4-epoxycyclohexylmethyl - 3',4'-epoxycyclohexanecarboxylate (ECC), with trade name CYRACURE UVR-6105 (IGM Resins, Barcelona, Spain) with an epoxy equivalent of $130 \mathrm{~g} / \mathrm{eq}$, and a manufacturer specified viscosity of 300 to $450 \mathrm{mPa} \cdot \mathrm{s}$ was used. An antimony hexafluoride-based catalyst for thermal initiated cationic polymerization (CI) with trade name K-PURE ${ }^{\circledR}$ CXC-1612 (King Industries, Norwalk, CT, USA) was used, along with the stabilizing agent triethanolamine (TEA, $149.19 \mathrm{~g} / \mathrm{mol}$ ) (Sigma Aldrich, Madrid, Spain). The stabilizing agent was used simply to control the acidity of the reaction medium and avoid premature polymerization. A 50\% solution (by weight) of the CI was prepared using propylene carbonate as the solvent. The solution contained $5 \%$ (by weight) of TEA, so that the TEA:CI weight ratio was 0.1. All raw materials were used without further purification. The dual-curing formulations were prepared simply by taking $2 \mathrm{phr}$ of the CI solution (with a resulting $\mathrm{CI}$ concentration of $1 \mathrm{phr}$ ) to a $5 \mathrm{ml}$ vial, adding ECC and finally Spot-HT. Finally, 2\% (by weight) of an azo red dye (Spot-A Materials, Barcelona, Spain) was added to the final mixture. The mixtures were coded with respect to their ECC content as $E x$, where $x$ represents the weight percentage of ECC. The formulations were wrapped in aluminum foil and stored in a fridge before analysis, in order to prevent premature activation of both acrylate and epoxy polymerization reactions. Table 1 shows the composition of the studied formulations. Finally, a peroxidic radical initiator 1,1-di(t-amylperoxy)-cyclohexane with trade name LUPEROX 531M60 (LUP hereafter) (ARKEMA, Colombes, France) was added to some formulations at $0.25 \%$ by weight, to study its effect.

Differential scanning calorimetry (DSC) was used to monitor monomer conversions during polymerizations and also for thermal $T_{\mathrm{g}}$ determinations. A Mettler DSC821 thermal analyzer (Mettler Toledo, Barcelona, Spain) equipped with a Hamamatsu

Table 1. Composition of the studied formulations.

\begin{tabular}{|l|c|c|c|}
\hline Formulation & $\begin{array}{c}\text { Spot-HT } \\
{[\mathbf{w t} \% \mathbf{]}}\end{array}$ & $\begin{array}{c}\text { ECC } \\
{[\mathbf{w t} \% \mathbf{0}}\end{array}$ & $\begin{array}{c}\text { CI } \\
{[\mathbf{w t} \% \mathbf{]}}\end{array}$ \\
\hline Spot-HT & 100.00 & 0.00 & 0.00 \\
\hline E10 & 88.24 & 9.80 & 1.96 \\
\hline E20 & 78.43 & 19.61 & 1.96 \\
\hline E30 & 68.63 & 29.41 & 1.96 \\
\hline E40 & 58.82 & 39.22 & 1.96 \\
\hline E50 & 49.02 & 49.02 & 1.96 \\
\hline E100 & 0.00 & 98.04 & 1.96 \\
\hline
\end{tabular}


Lightningcure LC5 (Hg-Xe lamp, irradiation intensity $<2 \mathrm{~mW} \cdot \mathrm{cm}^{-2}$ ) (Hamamatsu, Barcelona, Spain) was used for the photocuring stage, and also for the thermal curing stage. The fractional conversion $\mathrm{x}$ of functional groups and the reaction rate $\mathrm{dx} / \mathrm{dt}$ are calculated using the Equation (1):

$x=\frac{\Delta h}{\Delta h_{\text {total }}}, \frac{\mathrm{d} x}{\mathrm{~d} t}=\frac{\frac{\mathrm{d} h}{\mathrm{~d} t}}{\Delta h_{\text {total }}}$

where $\Delta h$ is the heat released up to a given time/temperature, $\Delta h_{\text {total }}$ is the total reaction heat evolved and $\mathrm{dh} / \mathrm{dt}$ is the heat flow.

A Mettler DSC3 + refrigerant cooled thermal analyzer (Mettler Toledo, Barcelona, Spain) was used for thermal $T_{\mathrm{g}}$ measurements. In all DSC scans, the heating rate was $10^{\circ} \mathrm{C} / \mathrm{min}$, except stated otherwise.

Fourier transform Infrared Spectrometry (FTIR) was used to qualitatively verify the conversion of acrylate and epoxy groups. The FTIR spectrometer was a Brucker Vertex 70 (Bruker Optics Inc., Billerica, MA, USA) equipped with an attenuated total reflection (ATR) accessory (GoldenGate ${ }^{\mathrm{TM}}$ ) (Specac Ltd., Orpington, UK) and with a temperature control unit. Dynamic mechanical analysis (DMA) was used to obtain storage modulus and tan delta curves of intermediate and final materials. DMA was performed with a TA Instruments DMA Q800 device (TA Instruments, New Castle, DE, USA) using single cantilever clamp at a frequency of $1 \mathrm{~Hz}$ and $0.05 \%$ strain, in a temperature range sufficiently wide to allow a full observation of network relaxation. The heating rate in all DMA scans was $3{ }^{\circ} \mathrm{C} / \mathrm{min}$.

Soluble fraction analysis was performed on intermediate and final materials to determine the amount of their extractables: dichloromethane was used as a solvent under full reflux conditions overnight. Stability tests were performed on uncured samples stored for prolonged durations under isothermal conditions (in a refrigerator at $8^{\circ} \mathrm{C}$ and in an oil bath at $32^{\circ} \mathrm{C}$ ). Residual polymerization heats of stability samples were measured using DSC.

UV-cured and fully cured samples for DSC, FTIR, DMA analysis, and solubility tests were prepared in a prismatic rectangular mold $\left(c a .50 \times 12 \times 1.5 \mathrm{~mm}^{3}\right)$ made of teflon and glass. UV flood curing was performed in a Vilber Lourmat UV-oven (Vilber Lourmat Sté, Collégien, France) equipped with $365 \mathrm{~nm}$ lamps with a light intensity of $4 \mathrm{~mW} / \mathrm{cm}^{2}$. Samples were irradiated on both sides for a period of time sufficient to ensure uniform and maximum conversion throughout their thickness. Fully cured samples were prepared in a Memmert natural convection oven (Memmert GmbH + Co., Schwabach, Germany) treating the UV-cured samples at $120^{\circ} \mathrm{C}$ for one hour and at $180^{\circ} \mathrm{C}$ for another hour.

A home-made mask image projection SL equipment (MIP-SL) [11] was employed to print specimens for a visual demonstration of proof-of-concept and DMA characterization.

Morphologies of fully cured materials were analyzed using atomic force microscopy. The equipment used was a scanning probe microscope (SPM) (NanoScope IIIa Multimode from Digital Instruments, Veeco Instruments Inc., Plainview, NY, USA) in tapping mode (TM-AFM). One beam cantilever $(125 \mathrm{~mm})$ with a silicon probe (curvature nominal radius of 5-10 nm) was used. Samples were cut using an ultramicrotome Leica Ultracut $\mathrm{R}$ with a diamond blade.

Compression tests were performed on neat Spot-HT and E50 formulations using an Instron 3366 Universal testing Machine (Instron, Barcelona, Spain), according to ASTM D695-15 standard. The nominal dimensions of the test specimen were $12.7 \times 12.7 \times$ $50.8 \mathrm{~mm}^{3}$. The test was performed at a constant displacement rate of $2.6 \mathrm{~mm} / \mathrm{min}$ until specimen failure or equipment limit $(10 \mathrm{kN})$.

\section{Results and discussion}

\subsection{Preliminary characterization}

First of all, the photocuring kinetics of neat acrylate and thermal curing kinetics of epoxy formulations were examined. Figure 3 shows the conversion and

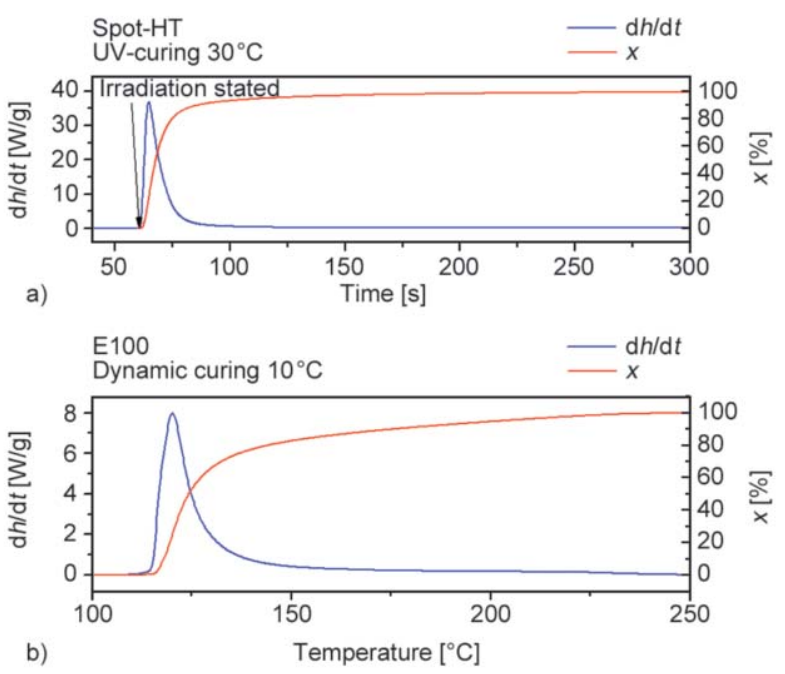

Figure 3. Comparison of the reaction rate and conversion for the isothermal UV-curing at $30^{\circ} \mathrm{C}$ of Spot-HT base formulation (a) and dynamic curing at $10^{\circ} \mathrm{C} / \mathrm{min}$ of E100 (b). 
rate curves obtained from DCS runs. The top graph in Figure 3 shows the isothermal photocuring of neat Spot-HT at $30^{\circ} \mathrm{C}$, whereas the bottom graph in Figure 3 shows a dynamic scan of E100 (neat ECC formulation) at $10^{\circ} \mathrm{C} / \mathrm{min}$. As can be seen, the photocuring of Spot-HT is complete within seconds upon irradiation. Polymerization of ECC starts at above $100^{\circ} \mathrm{C}$ and has a very sharp curing profile, indicating that the cationic curing system is thermally latent, in agreement with previous results [25].

Both reaction processes are highly exothermic. The acrylate photocuring releases $355 \mathrm{~J} / \mathrm{g}$ while the epoxy homopolymerization releases $620 \mathrm{~J} / \mathrm{g}$. The epoxy reaction enthalpy is in good agreement with previous reports $[25,26]$. The acrylate reaction enthalpy agrees well with previous (unpublished) results from our research group (ca. 100 kJ/eq). In Figure 4, FTIR spectra of liquid/uncured and solid/cured pure Spot-HT and ECC formulations (E100) are given. One can verify the virtually quantitative conversion of acrylate groups in Spot-HT after UV-curing and the quantitative conversion epoxy groups in E100 after thermal treatment.

It was also verified that exposure to UV light did not produce any effect on the ECC formulation (results not shown) and that the thermal curing of Spot-HT was only activated at temperatures higher than $180^{\circ} \mathrm{C}$. Such evidence suggested that ECC and the cationic initiator CI could be added to the Spot-HT formulation in order to obtain dual-curing formulations with storage stability (i.e. no reaction at room temperature and under dark conditions) and a controlled curing sequence as follows: a $1^{\text {st }}$ stage consisting of the
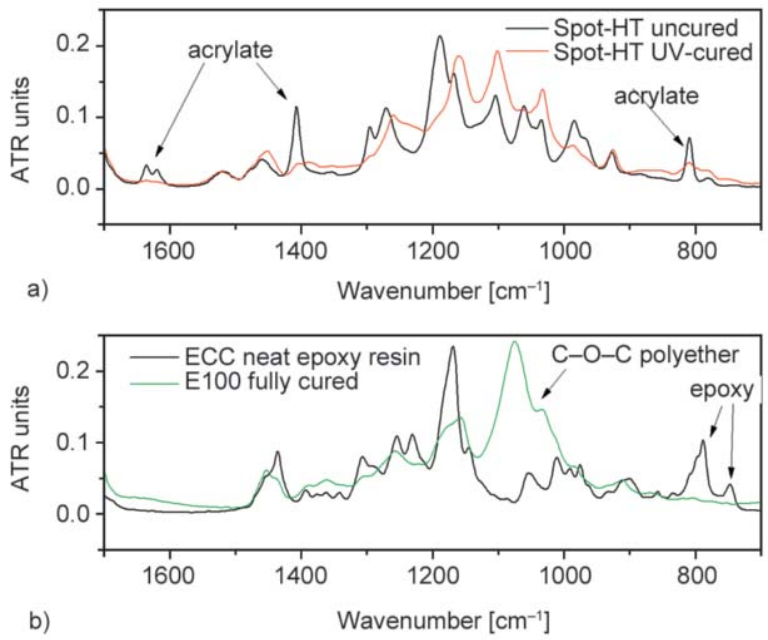

Figure 4. FTIR spectra of uncured and cured Spot-HT (a) and neat epoxy (b) formulations.
UV/visible-light-induced photopolymerization of acrylates at room temperature, followed by a $2^{\text {nd }}$ stage at an elevated temperature to thermally activate the cationic homopolymerization of ECC.

Next, the curing kinetics of dual formulations was analyzed. It was observed that the more the weight percentage of ECC, the less intense were the DSC heat flow peaks during the photocuring process, as can be expected due to the dilution of the acrylate monomers in the reaction medium. However, from a practical point of view, the conversion profiles remained unaltered, as can be seen in Figure 5.

The dilution effect caused by the addition of the epoxy component should be analyzed. One might expect that the dilution of both the acrylate and the photoinitiator would have a decelerating effect, according to the radical photopolymerization model outlined by Decker [27], assuming continuous irradiation, pseudo-steady state initiator concentration, and bimolecular termination, see Equation (2):

$-\frac{\mathrm{d} M}{\mathrm{~d} t}=k_{\mathrm{P}} \cdot\left(\frac{\phi_{\mathrm{i}} \cdot I_{\mathrm{a}}}{k_{\mathrm{t}}}\right)$

where $k_{\mathrm{P}}$ and $k_{\mathrm{t}}$ are the propagation and termination rate constants, $M$ is the concentration of monomer (acrylate), and $\phi_{\mathrm{i}} \cdot I_{\mathrm{a}}$ is the initiation rate expressed in terms of quantum yield of the photolysis $\left(\phi_{\mathrm{i}}\right)$ and intensity absorbed and $I_{\mathrm{a}}$. Given that the dilution of Spot-HT facilitates light penetration, photolysis and photoinitiation rate would be somewhat enhanced, therefore making up for the decrease in photoinitiator content. Nevertheless, the addition of epoxy seems to moderate the irradiation heat flow peaks (compare the peak heat flow rates in Figure 2).

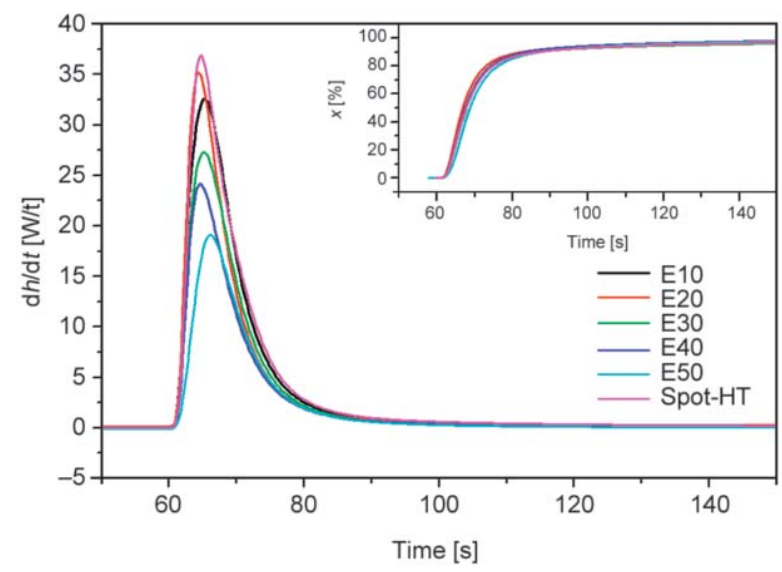

Figure 5. Effect of epoxy content on photocuring kinetics. PhotoDSC experiments carried out at $30^{\circ} \mathrm{C}$. Main graph: DSC Heat flow; Inset: conversion. 


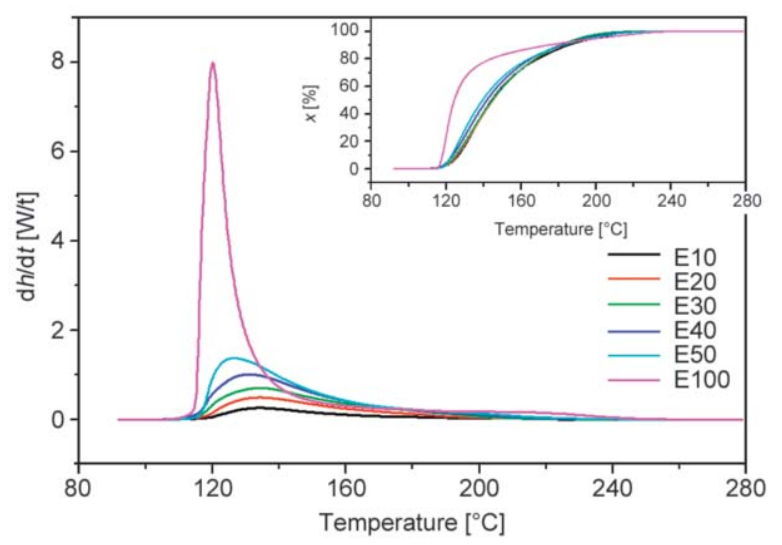

Figure 6. Dynamic curing at $10^{\circ} \mathrm{C} / \mathrm{min}$ of Ex formulations. Main graph: DSC heat flow; Inset: Epoxy conversion.

Figure 6 shows the results of the analysis of the thermal post-curing stage after the photocuring process. It is seen that as the Spot-HT content increases, the epoxy homopolymerization rate decreases, as expected. This is indicated by a milder DSC heat flow peak. The Spot-HT part not only dilutes the epoxy concentration, but it also slows down the epoxy reaction due to the ester groups in its structure by increasing the ratio of ester:epoxy groups in the reactive system. This inhibition effect was previously reported by Crivello and Varlemann [28]. Polyether structures are also known to delay the curing process through the formation of dormant species [29].

Table 2 summarizes the results of the calorimetric analysis of the different formulations. The reaction heats of the first and second stages decrease and increase, respectively, with increasing epoxy monomer content proportionally. Indeed, it was verified that the heat evolved per epoxy equivalent in the second stage was around $80-85 \mathrm{~kJ} / \mathrm{mol}$, in good agreement with previous reports $[25,26]$. This indicates the quantitative conversion of all monomers at both stages. This was also verified by FTIR, as evidenced

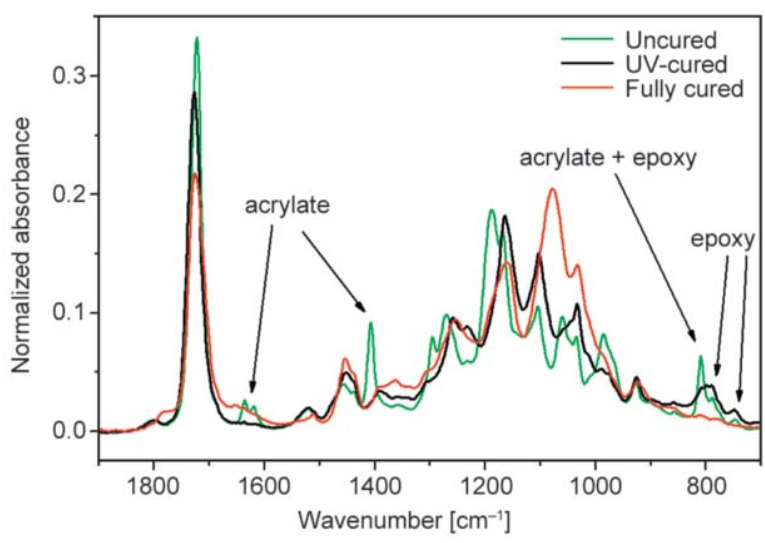

Figure 7. FTIR spectrometry results of E30 uncured, UVcured, and fully-cured formulation.

in Figure 7 for E30 formulation. The choice of this formulation for FTIR analysis was arbitrary. Upon comparison of the uncured and UV-cured spectra, it can be observed that the characteristic bands of the $\mathrm{C}=\mathrm{C}$ of the acrylate group at 800,1408 and 1620 $36 \mathrm{~cm}^{-1}$ (double peak) have disappeared after the photocuring process, therefore confirming completion of the first reaction of the dual-curing system. Similar results were obtained for all the other dual formulations. The quantitative reaction of epoxy groups after the thermal treatment was confirmed by the disappearance of the characteristic bands at $750-800 \mathrm{~cm}^{-1}$ And the appearance of a band around 1050 $1100 \mathrm{~cm}^{-1}$ typical of polyether $\mathrm{C}-\mathrm{O}-\mathrm{C}$ bonds.

In Table 2 it is also observed that the glass transition temperature after the photocuring stage, $T_{\mathrm{g}, 1}$, decreases with increasing epoxy content, as expected since the glass transition temperature of the unreacted ECC is about $-70^{\circ} \mathrm{C}$. This implies that materials with a high ECC content will be in the rubbery state at room temperature after photocuring, in contrast with the neat Spot-HT material. On the other hand, the glass transition temperature after $2^{\mathrm{n}} \mathrm{d}$ thermal stage, $T_{\mathrm{g}, 2}$, increases with increasing epoxy content

Table 2. Heats of reaction, $T_{\mathrm{g}}$, and extractable content of dual formulations.

\begin{tabular}{|l|c|c|c|c|c|}
\hline \multicolumn{1}{|c|}{ Formulation } & $\begin{array}{c}\Delta \boldsymbol{h}_{\mathbf{1}} \text { st } \\
{\left[\mathbf{J}^{-\mathbf{1}}\right]}\end{array}$ & $\begin{array}{c}\Delta \boldsymbol{h}_{\mathbf{}^{\text {nd }}} \\
{\left[\mathbf{J} \cdot \mathbf{g}^{-\mathbf{1}}\right]}\end{array}$ & $\begin{array}{c}\boldsymbol{T}_{\mathbf{g}, \mathbf{1}} \\
{\left[{ }^{\circ} \mathbf{C}\right]}\end{array}$ & $\begin{array}{c}\boldsymbol{T}_{\mathbf{g}, \mathbf{2}} \\
{\left[{ }^{\circ} \mathbf{C}\right]}\end{array}$ & $\begin{array}{c}\text { Gel frac. after UV } \\
{[\mathbf{w t} \text { o] }}\end{array}$ \\
\hline Spot-HT & 346.9 & 8.2 & 51 & 52 & 96.9 \\
\hline E10 & 323.7 & 63.5 & 31 & 65 & 85.5 \\
\hline E20 & 293.5 & 129.7 & -9 & 78 & 76.5 \\
\hline E30 & 273.7 & 191.6 & -25 & 92 & 69.9 \\
\hline E40 & 224.5 & 256.3 & -36 & 97 & 57.4 \\
\hline E50 & 200.1 & 310.7 & -42 & 110 & 48.1 \\
\hline E100 & - & 615.0 & -60 & $170^{*}$ & - \\
\hline
\end{tabular}

\footnotetext{
${ }^{*}$ Temperature at loss modulus peak in DMA - approximates $T_{\mathrm{g}}$ determined by DSC
} 
as expected due to the high $T_{\mathrm{g}}$ of the epoxy homopolymer network [25]. The $T_{\mathrm{g}}$ of neat epoxy (E100) fully cured DSC could not detect material due to its extremely broad glass transition profile. Instead, the temperature at loss modulus peak measured by DMA is provided as this value can be used as a fair approximation of the $T_{\mathrm{g}}$ measured by DSC [30]. The weights of extractable fractions of the intermediate materials after prolonged submersion in boiling solvent (dichloromethane) are coherent, which indicates that an acrylate network has formed after the first photocuring stage. The values of the experimental residual (insoluble) fraction are highly comparable to the Spot-HT content of the formulations (see Table 1). However, in a DSC scan, the insoluble (gel) fraction exhibited a $T_{\mathrm{g}}$ which was $20^{\circ} \mathrm{C}$ higher than that of the UV-cured neat Spot-HT sample, suggesting that a small part of the acrylates did not get incorporated into the crosslinked gel. The fact that no significant acrylate absorption peaks were observed in the FTIR analysis of the E30 intermediate material suggests that these acrylates were indeed polymerized but apparently did not link with the infinite sized polymer (i.e. gel). However, after the thermal curing step, all materials had virtually $100 \%$ gel fraction.

In order to test the applicability of these dual-curing formulations, we selected the E30 formulation for a more detailed analysis since it was believed that this particular formulation is a good balance between improved mechanical properties and good storage stability (vide infra). Nevertheless, a compression test was performed on a different formulation, namely E50, since this formulation was expected to have the highest Young's modulus among the other formulations studied.

\subsection{Analysis of E30 dual curing formulation}

\subsubsection{Curing kinetics}

As indicated by the values of $T_{\mathrm{g}, 1}$ and $T_{\mathrm{g}, 2}$ in Table 2, E30 is a soft elastomer at the intermediate stage but cures to a densely crosslinked, hard thermoset after the second stage. Figure 5 evidenced that the photocuring stage is almost complete in a few seconds at ambient temperature, and Figure 6 suggested that $2^{\text {nd }}$ stage thermal epoxy homopolymerization has a latent character and that it could be completed in a short period at a moderate temperature. It was verified in an isothermal DSC scan that the $2^{\text {nd }}$ stage is almost complete in 1-2 hours at moderately elevated temperatures such as $130^{\circ} \mathrm{C}$ (results not shown). An induction period followed by a sharp activation is clearly observed at lower temperatures, evidencing the latent character of the epoxy homopolymerization taking place at the $2^{\text {nd }}$ stage. Tentatively, a mild thermal treatment procedure was established as follows: $1 \mathrm{~h}$ at $120^{\circ} \mathrm{C}$ followed by $1 \mathrm{~h}$ at $180^{\circ} \mathrm{C}$ to ensure complete conversion of all epoxy groups.

\subsubsection{Thermomechanical properties}

The crosslinking process during the thermal treatment of E30 intermediate material was monitored with DMA and compared with the curing process analyzed with DSC. Figure 8 compares the evolution of the storage modulus and DSC conversion at a heat ing rate of $3{ }^{\circ} \mathrm{C} / \mathrm{min}$ up to a temperature above which no heat release is measured in DSC. The evolution of the modulus follows a similar trend as the DSC conversion, as expected. The increase in modulus is, however, delayed with respect to the start of the curing process. The onset of the rise in modulus takes place when the DSC conversion is about $20 \%$. This point is close to the gel point of the epoxy network, which is in good agreement with the results reported by other authors [31] for the same homopolymerization of this neat epoxy resin.

The results indicate that, during the heating process, the modulus never drops below relaxed modulus determined with DMA (ca. $30 \mathrm{MPa}$ ). This concern stems from the fact that the alpha relaxation of this intermediate material is only partially complete at ambient temperature (vide infra), which is also the initial temperature of the DMA scan. However, during the initial heating phase, no additional softening was observed. Therefore, it is safe to assume that if the sample is mechanically consistent after the $3 \mathrm{D}$

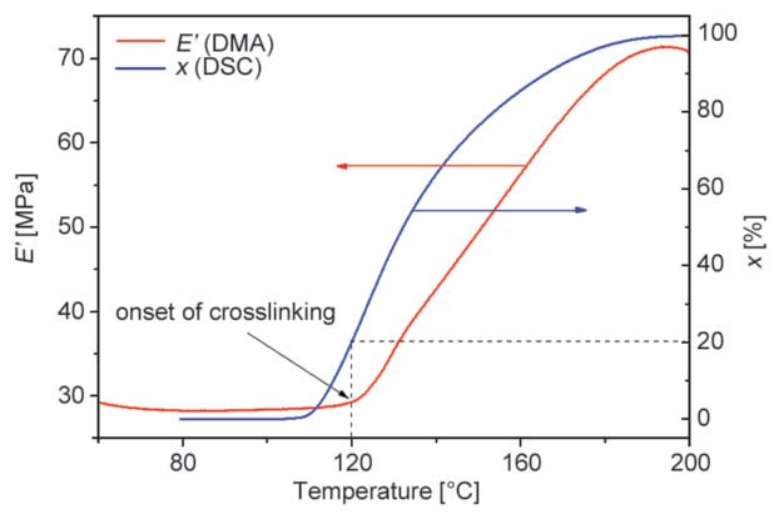

Figure 8. Conversion and storage modulus is plotted against time for the thermal curing stage of E30. Same heating programme was used in both DMA and DSC. 
printing process, heating of the printed specimen in an oven to carry out the second reaction would not result in a loss of mechanical properties.

To compare the intermediate and final E30 materials, in Figure 9 the storage moduli and tan delta curves are plotted against temperature. The tan delta curves are unimodal, and the shape of the curves of neat Spot-HT and E30 samples are similar, hinting a good compatibility of the two networks, which must be confirmed with further analysis. A contributing factor to compatibility is the H-bonding interactions between the amine hydrogens of the polyacrylate and the carboxylic oxygens of the polyether structures (see Figure 2). As can be seen, modulus and alpha relaxation temperature (tan delta peak) increases significantly after the thermal $2^{\text {nd }}$ stage. The epoxy curing helped the tan delta peak temperature to increase about $80^{\circ} \mathrm{C}$. The rubbery moduli of the intermediate and final material are measured as 24 and $70 \mathrm{MPa}$, respectively. The change in both properties can be easily explained taking into account that the material structure changes from an acrylate network swollen in unreacted monomer to a fully cross-linked, interpenetrated network structure combining acrylate and epoxy homopolymer networks. The tan delta peak temperature of the fully cured E30 material is $102^{\circ} \mathrm{C}$, which is about $30-40^{\circ} \mathrm{C}$ higher than that of the neat Spot-HT, which is $66^{\circ} \mathrm{C}$. This result is in agreement with the DSC data shown in Table 2. This implies that mechanical relaxation of the E30 network is much slower than that of Spot-HT, therefore resulting in higher and more stable modulus under mechanical load. This can facilitate the design of lightweight components with controllable mechanical properties. The broad relaxation profile of the final

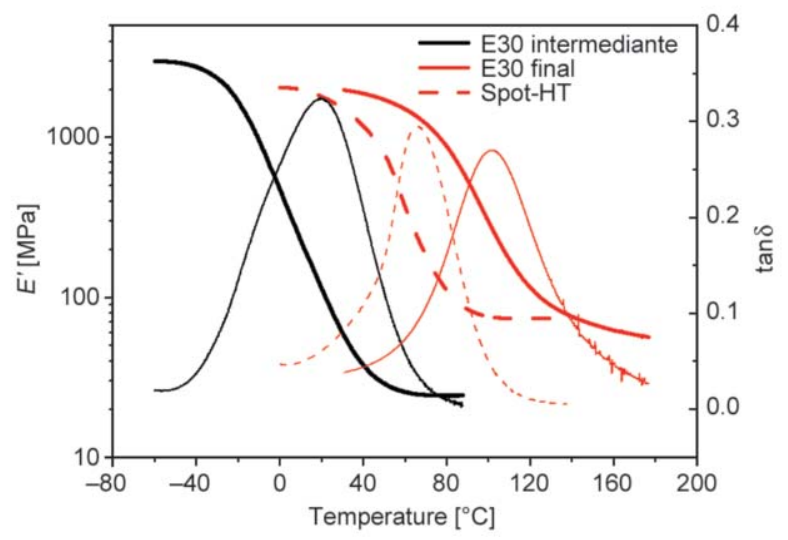

Figure 9. The evolution of storage modulus and tan delta upon thermal treatment of the E30 material. For comparison, the neat Spot-HT material is also presented (dashed curves). material is evident from its tan delta curve. This indicates that the modified materials have a more disperse network structure due to the coexistence of two polymer networks, and due to the densely crosslinked structure of the epoxy homopolymer network [25].

\subsubsection{Compression test}

To demonstrate further the added value of the epoxy component added to the neat Spot-HT resin, we selected the E50 formulation and performed a compression test, as explained in the experimental section. Nearly a 10 -fold increase in Young's modulus was recorded over the neat Spot-HT formulation. An exemplary stress-strain graph is shown in Figure 10 which demonstrates this vast improvement. In this particular test, Young's Moduli of Spot-HT and E50 were calculated as 185 and $1624 \mathrm{MPa}$, respectively.

\subsubsection{Nanomorphology}

In Figure 11, the AFM phase (left) and height (right) images of the fully cured samples of the neat components Spot-HT, E30, and E100 are given. As can be seen, Spot-HT and E100 materials exhibit a nanostructure of $7 \mathrm{~nm}$ and $10 \mathrm{~nm}$, respectively, characteristic of chainwise polymerizations [15, 32]. The presence of light and dark-colored patches and the typical height profiles (Figure 11, right) indicate a certain intrinsic heterogeneity at the nanometer scale which is also a common observation due to crosslinked nanogel nodules and clusters [15]. Nevertheless, all analyzed materials were homogeneous at the macroscopic scale. The nano-scale topology of E30 is very similar to the neat components, with a domain size of $7 \mathrm{~nm}$. This similarity points to good

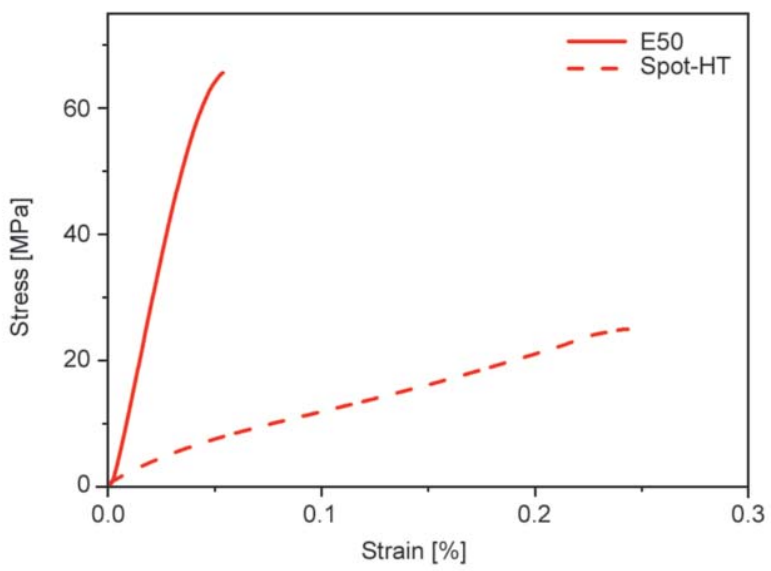

Figure 10. Stress-strain curves of the compression test performed on E50 and Spot-HT fully cured specimens. 


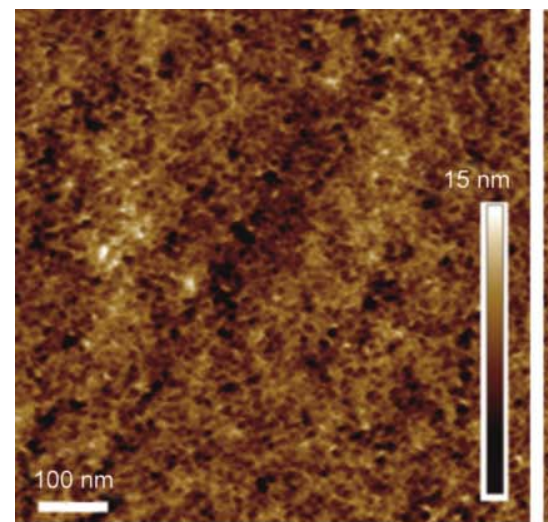

$\left.a_{1}\right)$

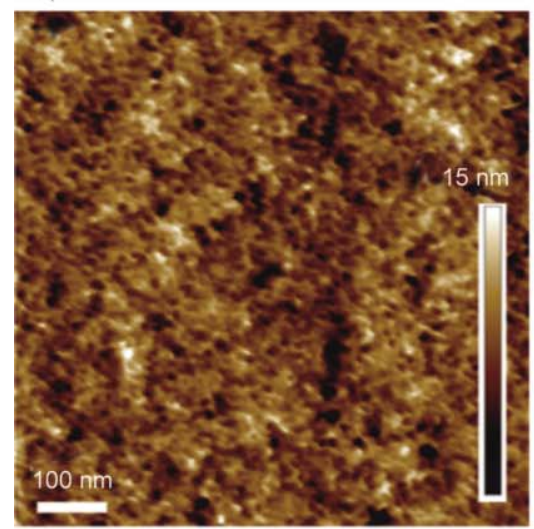

$\left.b_{1}\right)$

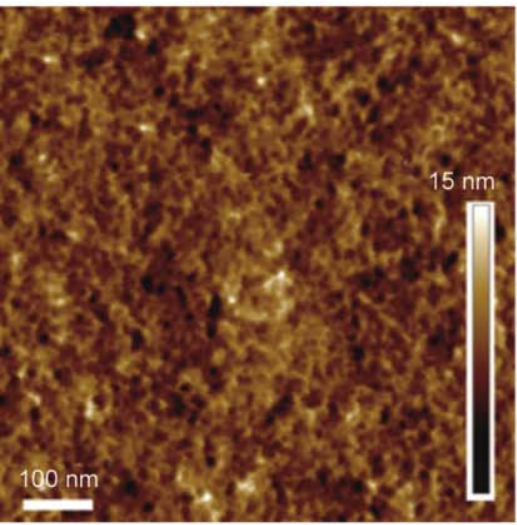

$\left.c_{1}\right)$

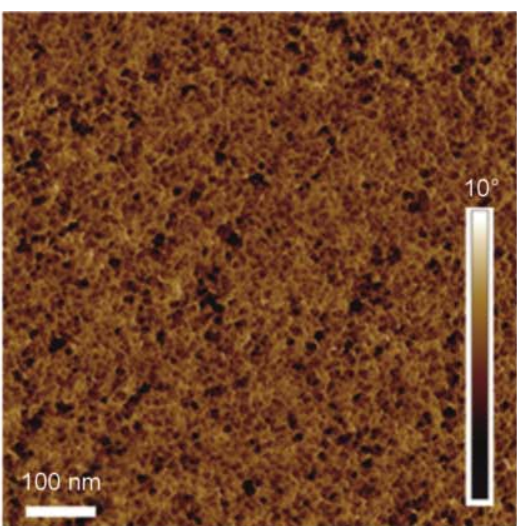

$\left.a_{2}\right)$

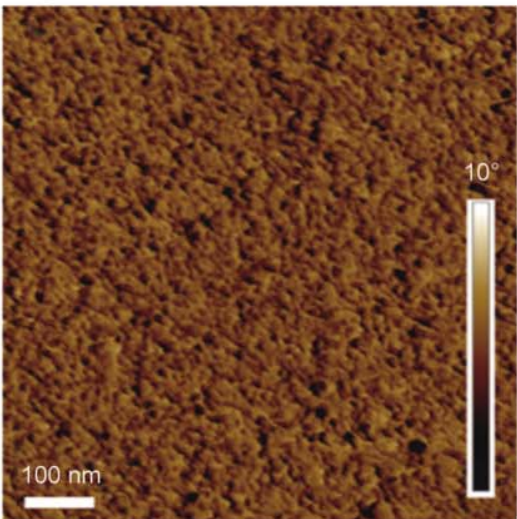

$\left.b_{2}\right)$

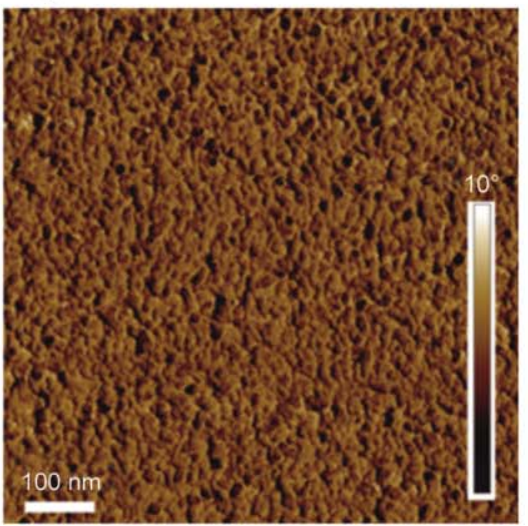

$c_{2}$ )

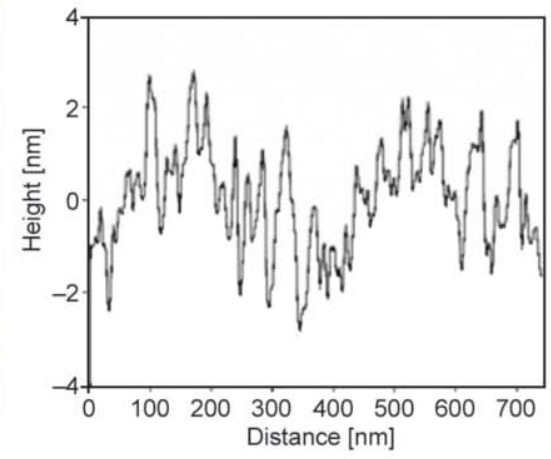

$\left.a_{3}\right)$

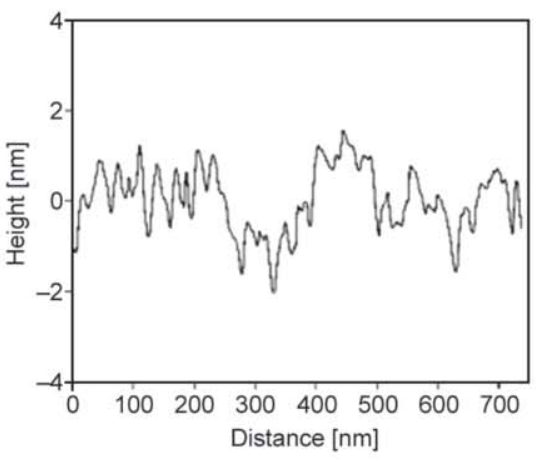

$\left.b_{3}\right)$

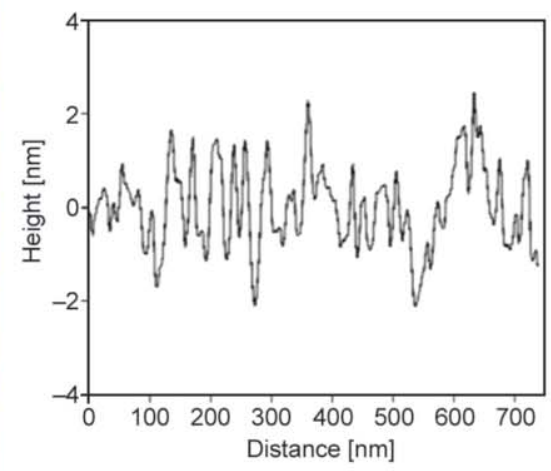

$\left.\mathrm{c}_{3}\right)$

Figure 11. AFM phase (left) and height (right) images of fully cured Spot-HT (a), E30 (b), and E100 (c) materials. Typical AFM height profile of each system is shown on the right.

compatibility between the two different polymeric networks. This compatibility was also corroborated by DMA, as the E30 material exhibited a unimodal tan delta peak (vide supra).

\subsubsection{Storage stability}

According to previous results from Isarn et al. [25], showing storage stability of up to 16 weeks for a neat epoxy formulation with the same cationic initiator system, it was expected that the dual formulations would have comparable storage stability unless some interaction between the different components takes place. In the present work, we verified that the
UV-curing and thermal curing steps of uncured formulations were also unaffected by storage at the prescribed conditions (Oil bath at $32^{\circ} \mathrm{C}$ ). Preliminary kinetics were established by analyzing dynamic DSC data by isoconversional integral methods explained elsewhere [33,34]. As shown in Figure 12, we estimate an induction period (for a conversion of $1 \%$ ) of 44 days at $32^{\circ} \mathrm{C}$ (oil bath temperature).

Unreacted samples stored in the oil bath and analyzed on a weekly basis by DSC confirmed this preliminary estimation. As can be seen in Table 3, the reaction heats of uncured E30 samples kept in the oil bath remained practically unchanged even after 


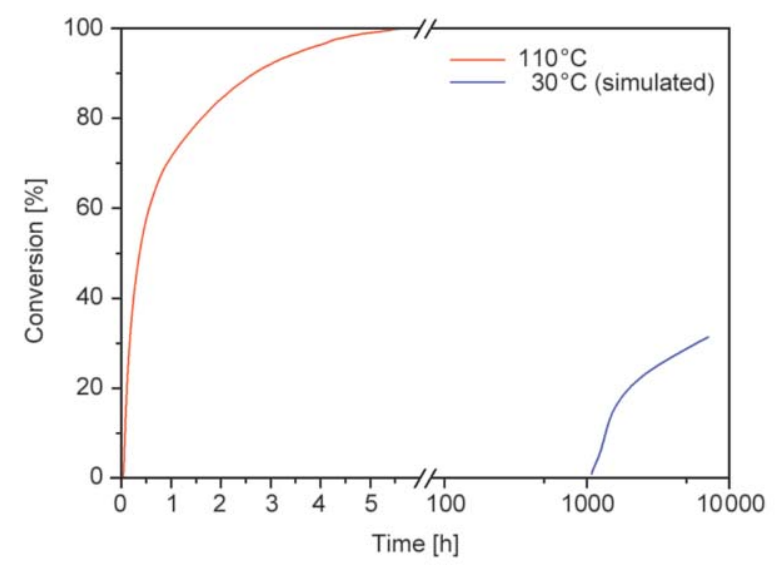

Figure 12. Conversion-time plots of the epoxy homopolymerization process (second curing stage) of E30 at $110^{\circ} \mathrm{C}$, after $\mathrm{UV}$-curing, and at $32^{\circ} \mathrm{C}$ without UV-curing.

Table 3. DSC analysis of the storage stability of E30.

\begin{tabular}{|c|c|c|}
\hline Week & $\begin{array}{c}\Delta \boldsymbol{H} \text { Stage 1 } \\
{\left[\mathbf{J} \cdot \mathbf{g}^{-1}\right]}\end{array}$ & $\begin{array}{c}\Delta \boldsymbol{H} \text { Stage } 2 \\
{\left[\mathbf{J} \cdot \mathbf{g}^{-1}\right]}\end{array}$ \\
\hline 1 & 264 & 191 \\
\hline 2 & 264 & 192 \\
\hline 3 & 267 & 187 \\
\hline 4 & 245 & 183 \\
\hline 5 & 260 & 187 \\
\hline 6 & 261 & 188 \\
\hline 7 & 253 & 188 \\
\hline 8 & 261 & 188 \\
\hline 9 & 271 & 186 \\
\hline
\end{tabular}

L1 9 weeks, surpassing the preliminary isoconversional L2 simulation. Moreover, the shape of the curing exoL3 therms during the $1^{\text {st }}$ stage (UV-induced acrylate hoL4 mopolymerization) and $2^{\text {nd }}$ stage (thermally activat-

L5 ed epoxy homopolymerization) hardly changed, as

L6 can be seen in Figure 13. From a practical point of
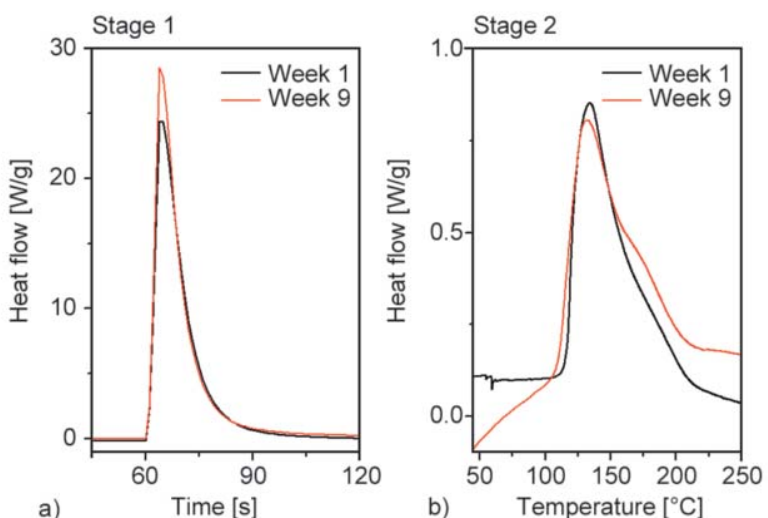

Figure 13. DSC heat flow curves of uncured ES30 after a storage period of 9 weeks. a) Shows the isothermal UV-cure at $30^{\circ} \mathrm{C}\left(1^{\text {st }}\right.$ stage $)$, and b) shows the dynamic curing at $10^{\circ} \mathrm{C} / \mathrm{min}\left(2^{\text {nd }}\right.$ stage $)$ after UV-curing. view, this is of crucial importance since it indicates that the SL process is unaffected and that only slight changes - if any - in resin viscosity would take place, therefore maintaining the processability of the liquid formulation in the SL machine.

\subsubsection{Stereolithography tests}

Home-made MIP-SL equipment [11] as depicted in Figure 1 was used to validate the dual curing concept. Since the viscosities of both the neat Spot-HT resin and ECC were similar, all the Ex mixtures we prepared had desirable viscosities for 3D printing. Figure 14 shows a printed test sample of E30 material. An azo red dye (added $2 \%$ by weight on total solids) was used to control light penetration in the resin and control layer thickness, which was set to 75 microns. Exposure time was set so as to ensure inter-layer adhesion. In the figure, it can be appreciated that good accuracy was obtained but nevertheless individual layers can be distinguished. The bust gained significant hardness after the second stage curing (i.e. thermal treatment). No loss of detail was observed whatsoever.

Samples of E30 formulation were printed with a dimension appropriate for DMA analysis. The samples were analyzed with DMA after thermal treatment in an oven for $1 \mathrm{~h}$ at $120^{\circ} \mathrm{C}$ followed by an additional hour at $180^{\circ} \mathrm{C}$. The printed final material exhibited a tan delta peak at a lower temperature than that of a benchmark sample manufactured in the laboratory (UV flood curing + thermal curing in the oven), as seen in Figure 15. This is possibly due to incomplete conversion of acrylic double bonds in the SL process. During 3D printing, it is sufficient to irradiate the layer until gelation in order to ensure mechanical consistency and effective build-up of the processed
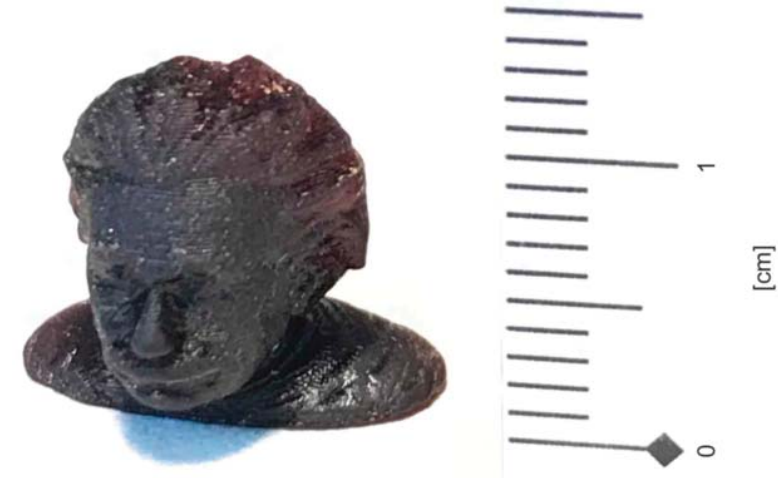

Figure 14. A bust of Dr. Einstein printed from the ES30 material. 


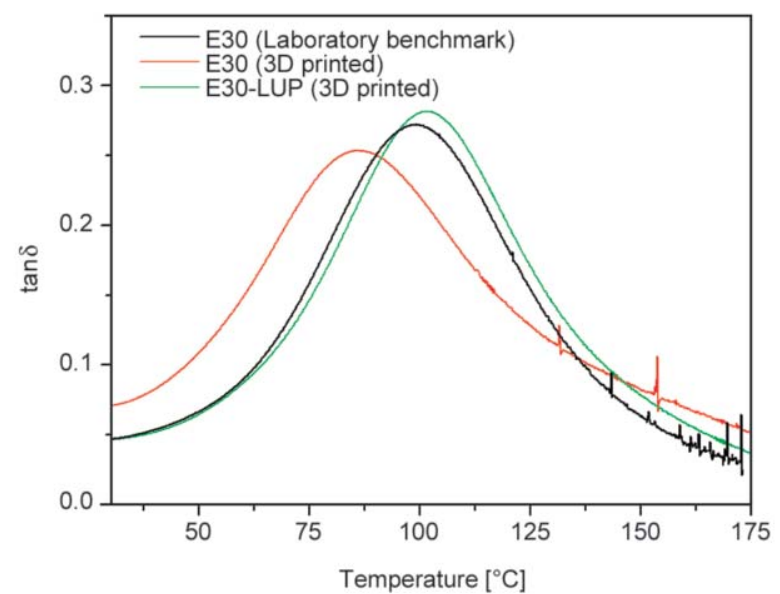

Figure 15. DMA $\tan \delta$ curves of SL printed and postcured ES30 specimens compared to a benchmark specimen whose photopolymerization process was carried out in a UV oven.

component. However, while further irradiation would ensure complete and uniform conversion throughout the component, printing times and thus overall costs would increase. Furthermore, a poor dimensional accuracy of the processed specimen would result [11]. Non-uniform, incomplete acrylate conversion and poor mechanical properties can thus be expected in an object printed with high accuracy (i.e. less irradiation).

However, this trade-off would be less of an issue if a thermal radical generator is used for the subsequent thermal post-curing stage. In that case, the unreacted double bonds can polymerize together with the epoxy part in the formulation. It was verified that the addition of $0.25 \mathrm{wt} \%$ of diperoxyketal radical initiator (LUP) could be used to promote the thermal radical polymerization of acrylates of Spot-HT within the same temperature range of the epoxy homopolymerization in the dual-curing system, as can be seen

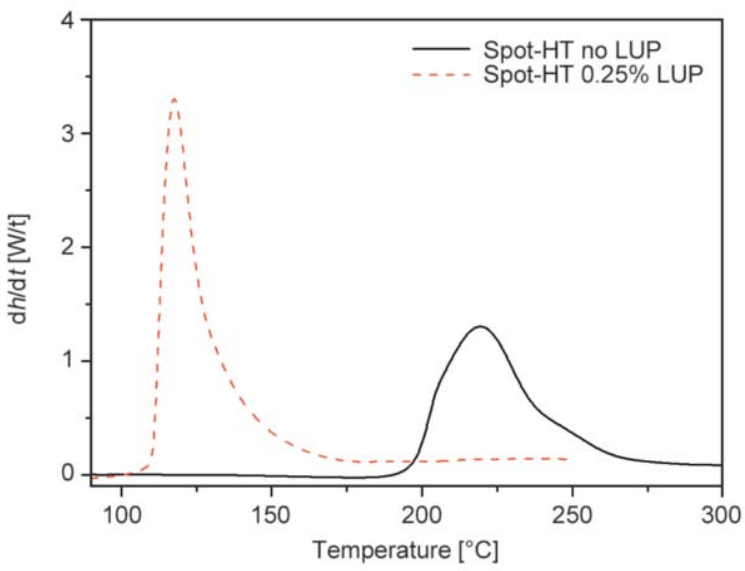

Figure 16. Dynamic curing at $10^{\circ} \mathrm{C} / \mathrm{min}$ of Spot-HT without and with addition of $0.25 \mathrm{wt} \%$ of LUP.

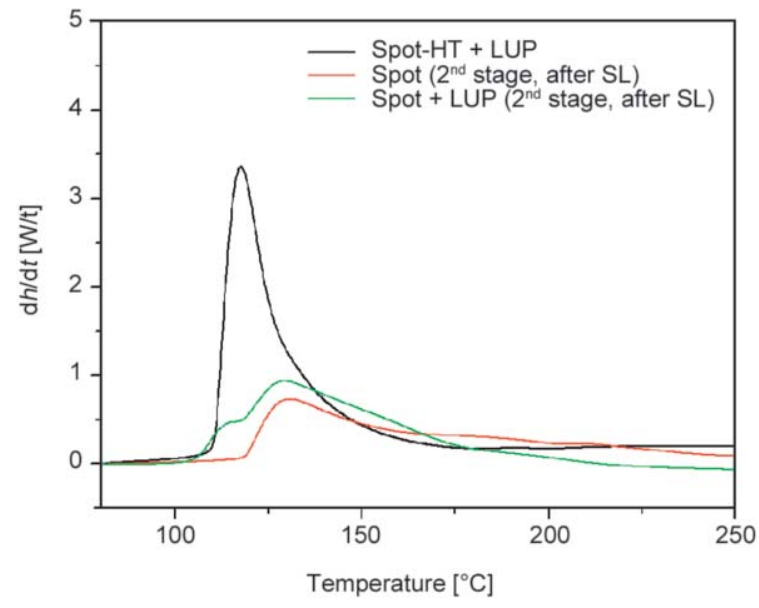

Figure 17. Heat flow curves at $10^{\circ} \mathrm{C} / \mathrm{min}$ of LUP initiated acrylate homopolymerization in neat Spot-HT and in E30.

in Figure 16. and also showing a latent character (i.e. sharp reaction onset upon heating).

Indeed, Figure 17 shows that the printed E30 formulation containing LUP, upon heating, produces a small curing exotherm before the $2^{\text {nd }}$ stage epoxy homopolymerization. This can be attributed to the radical homopolymerization of remaining unreacted acrylate groups promoted by LUP. This small exotherm is not observed in the printed E30 sample without LUP.

In consequence, the thermal treatment that is necessary for the epoxy homopolymerization reaction in the dual-curing system would simultaneously promote the complete reaction of remaining acrylates in dual formulations containing an additional $0.25 \mathrm{wt} \%$ of LUP. The positive effect of consuming all remaining acrylates in the thermal step was confirmed once more in SL tests. E30-LUP formulation was prepared and parts were printed with dimensions appropriate to DMA. Specimens were analyzed after the usual thermal post-cure (i.e. $1 \mathrm{~h}$ at $120^{\circ} \mathrm{C}$ followed by $1 \mathrm{~h}$ at $180^{\circ} \mathrm{C}$ ). Figure 15 shows that formulation E30-LUP has now a similar alpha relaxation behavior and the same tan delta peak temperature as the fully cured benchmark specimen of E30 produced in the laboratory. The storage stability of E30-LUP formulation was not studied in detail but it is presumably comparable to that of E30, given the latent character of LUP (see Figure 17).

\section{Conclusions}

A novel dual-curing stereolithographic resin was formulated by mixing an epoxy monomer into a commercially available multi-acrylate SL resin. After an 
initial SL printing step at ambient temperature, the material is thermally treated to initiate cationic epoxy homopolymerization, as well as to finish off the remaining acrylate monomers. The latter is accomplished with the help of a thermally activated radical initiator. As was characterized by calorimetry, FTIR spectrometry and solubility tests, these new materials have superior thermomechanical properties due to two factors: the incorporation of the more densely crosslinked epoxy network and the thermally facilitated increased conversion of acrylates. AFM analysis showed that the nanomorphology of the dual materials resembled that of their neat constituents, with a homogeneous distribution of nano-sized domains. The particular E30 formulation showed excellent storage stability, hinting to the processing flexibility offered by the Ex family. Samples of this formulation could be easily printed with high resolutions. Furthermore, a nearly 10-fold increase in Young's modulus over the neat acrylate resin was demonstrated by the E50 formulation. Similar to all truly sequential dual-curing thermoset formulations, a wide range of intermediate and final properties can be tailored as desired by simply changing formulation compositions. As these novel materials can match, in thermomechanical properties, conventional thermosets based on acrylates and/or epoxies, it could be argued that the potential of these materials in the SL context may go beyond decorative applications or prototyping. Further research should, therefore, focus on mechanically characterizing structural and functional materials with different shapes and sizes printed with these novel SL resins.

\section{Acknowledgements}

The authors would like to thank MCIU (Ministerio de Ciencia, Innovación y Universidades) (MAT2017-82849-C2-1-R and MAT2017-82849-C2-2-R), FEDER (Fondo Europeo de Desarrollo Regional) (MAT2017-82849-C2-1-R, MAT201782849-C2-2-R and BASE3D) and Generalitat de Catalunya (2017-SGR-77 and Serra Húnter program) for the financial support. We also thank King Industries Inc. for supplying the catalyst.

\section{References}

[1] Hofmann M.: 3D printing gets a boost and opportunities with polymer materials. ACS Macro Letters, 3, 382-386 (2014).

https://doi.org/10.1021/mz4006556
[2] Ligon S. C., Liska R., Stampfl J., Gurr M., Mülhaupt R.: Polymers for 3D printing and customized additive manufacturing. Chemical Reviews, 117, 10212-10290 (2017). https://doi.org/10.1021/acs.chemrev.7b00074

[3] Gross B. C., Erkal J. L., Lockwood S. Y., Chen C., Spence D. M.: Evaluation of 3D printing and its potential impact on biotechnology and the chemical sciences. Analytical Chemistry, 86, 3240-3253 (2014). https://doi.org/10.1021/ac403397r

[4] Przeradzka M. A., van Bochove B., Bor T. C., Grijpma D. W.: Phase-separated mixed-macromer hydrogel networks and scaffolds prepared by stereolithography. Polymers for Advanced Technologies, 28, 1212-1218 (2017). https://doi.org/10.1002/pat.3916

[5] Makvandi P., Esposito Corcione C., Paladini F., Gallo A. L., Montagna F., Jamaledin R., Pollini M., Maffezzoli A.: Antimicrobial modified hydroxyapatite composite dental bite by stereolithography. Polymers for Advanced Technologies, 29, 364-371 (2018).

https://doi.org/10.1002/pat.4123

[6] Rolland J. P.: Functional materials for 3D manufacturing using carbon's CLIP technology. Journal of Photopolymer Science and Technology, 29, 451-452 (2016). https://doi.org/10.2494/photopolymer.29.451

[7] Tumbleston J. R., Shirvanyants D., Ermoshkin N., Janusziewicz R., Johnson A. R., Kelly D., Chen K., Pinschmidt R., Rolland J. P., Ermoshkin A., Samulski E. T., DeSimone J. M.: Continuous liquid interface production of 3D objects. Science, 347, 1349-1352 (2015). https://doi.org/10.1126/science.aaa2397

[8] Hassan R. U., Jo S., Seok J.: Fabrication of a functionally graded and magnetically responsive shape memory polymer using a $3 \mathrm{D}$ printing technique and its characterization. Journal of Applied Polymer Science, 135, 45997/1-45997/7 (2018).

https://doi.org/10.1002/app.45997

[9] Crivello J. V., Reichmanis E.: Photopolymer materials and processes for advanced technologies. Chemistry of Materials, 26, 533-548 (2014). https://doi.org/10.1021/cm402262g

[10] Sun C., Fang N., Wu D. M., Zhang X.: Projection microstereolithography using digital micro-mirror dynamic mask. Sensors and Actuators A: Physical, 121, 113-120 (2005).

https://doi.org/10.1016/j.sna.2004.12.011

[11] Bonada J., Muguruza A., Fernández-Francos X., Ramis $\mathrm{X}$. Optimisation procedure for additive manufacturing processes based on mask image projection to improve $\mathrm{z}$ accuracy and resolution. Journal of Manufacturing Processes, 31, 689-702 (2018). https://doi.org/10.1016/j.jmapro.2018.01.004 
[12] Huang B., Du Z., Yong T., Han W.: Preparation of a novel hybrid type photosensitive resin for stereolithography in 3D printing and testing on the accuracy of the fabricated parts. Journal Wuhan University of Technology, Materials Science Edition, 32, 726-732 (2017). https://doi.org/10.1007/s11595-017-1659-x

[13] Esposito Corcione C., Striani R., Montagna F., Cannoletta D.: Organically modified montmorillonite polymer nanocomposites for stereolithography building process. Polymers for Advanced Technologies, 26, 92 98 (2015).

https://doi.org/10.1002/pat.3425

[14] Jian Y., He Y., Sun Y., Yang H., Yang W., Nie J.: Thiolepoxy/thiol-acrylate hybrid materials synthesized by photopolymerization. Journal of Materials Chemistry C, 1, 4481-4489 (2013). https://doi.org/10.1039/c3tc30360h

[15] Pascault J-P., Sautereau H., Verdu J., Williams R. J. J.: Thermosetting polymers. Marcel Dekker, New York (2002).

[16] Lantean S., Roppolo I., Sangermano M., Pirri C. F., Chiappone A.: Development of new hybrid acrylic/ epoxy DLP-3D printable materials. Inventions, 3, 29/129/13 (2018).

https://doi.org/10.3390/inventions3020029

[17] Flores M., Tomuta A. M., Fernández-Francos X., Ramis X., Sangermano M., Serra À.: A new two-stage curing system: Thiol-ene/epoxy homopolymerization using an allyl terminated hyperbranched polyester as reactive modifier. Polymer, 54, 5473-5481 (2013). https://doi.org/10.1016/j.polymer.2013.07.056

[18] Fernández-Francos X., Konuray A-O., Belmonte A., De la Flor S., Serra À., Ramis X.: Sequential curing of off-stoichiometric thiol-epoxy thermosets with a custom-tailored structure. Polymer Chemistry, 7, 2280 2290 (2016). https://doi.org/10.1039/C6PY00099A

[19] Morancho J. M., Ramis X., Fernández-Francos X., Salla J. M., Konuray A. O., Serra À.: Curing of off-stoichiometric amine-epoxy thermosets. Journal of Thermal Analysis and Calorimetry, 133, 519-527 (2018). https://doi.org/10.1007/s10973-018-7158-2

[20] Konuray O., Areny N., Morancho J. M., FernándezFrancos X., Serra À., Ramis X.: Preparation and characterization of dual-curable off-stoichiometric amineepoxy thermosets with latent reactivity. Polymer, 146, 42-52 (2018).

https://doi.org/10.1016/j.polymer.2018.05.040

[21] Romero M., Fernández-Francos X., Ramis X.: Sequential heat release: An innovative approach for the control of curing profiles during composite processing based on dual-curing systems. Polymer International, 68, 527545 (2019).

https://doi.org/10.1002/pi.5743
[22] Bailleul J-L., Sobotka V., Delaunay D., Jarny Y.: Inverse algorithm for optimal processing of composite materials. Composites Part A: Applied Science and Manufacturing, 34, 695-708 (2003). https://doi.org/10.1016/S1359-835X(03)00141-6

[23] Struzziero G., Skordos A. A.: Multi-objective optimisation of the cure of thick components. Composites Part A: Applied Science and Manufacturing, 93, 126-136 (2017). https://doi.org/10.1016/j.compositesa.2016.11.014

[24] Kuang X., Zhao Z., Chen K., Fang D., Kang G., Qi H. J.: High-speed 3D printing of high-performance thermosetting polymers via two-stage curing. Macromolecular Rapid Communications, 39, 1700809/1-1700809/8 (2018). https://doi.org/10.1002/marc.201700809

[25] Isarn I., Gamardella F., Massagués L., FernàndezFrancos X., Serra A., Ferrando F.: New epoxy composite thermosets with enhanced thermal conductivity and high $T_{\mathrm{g}}$ obtained by cationic homopolymerization. Polymer Composites, 53, E1760-E1769 (2018). https://doi.org/10.1002/pc.24774

[26] Fernandez X., Salla J. M., Serra A., Mantecón A., Ramis X.: Cationic copolymerization of cycloaliphatic epoxy resin with a spirobislactone with lanthanum triflate as initiator: I. Characterization and shrinkage. Journal of Polymer Science Part A: Polymer Chemistry, 43, 3421-3432 (2005).

https://doi.org/10.1002/pola.20801

[27] Decker C.: Kinetic study and new applications of UV radiation curing. Macromolecular Rapid Communications, 23, 1067-1093 (2002). https://doi.org/10.1002/marc.200290014

[28] Crivello J. V., Varlemann U.: Structure and reactivity relationships in the photoinitiated cationic polymerization of 3,4-epoxycyclohexylmethyl-3',4'-epoxycyclohexane carboxylate. ACS Symposium Series, 673, 8294 (1997). https://doi.org/10.1021/bk-1997-0673.ch007

[29] Matějka L., Chabanne P., Tighzert L., Pascault J. P.: Cationic polymerization of diglycidyl ether of bisphenol A. Journal of Polymer Science Part A: Polymer Chemistry, 32, 1447-1458 (1994) https://doi.org/10.1002/pola.1994.080320806

[30] Konuray O., Fernández-Francos X., Ramis X., Serra À.: Acetoacetate based thermosets prepared by dualMichael addition reactions. Polymers, 11, 1408/11408/13 (2019). https://doi.org/10.3390/polym11091408

[31] Kim Y-M., Kostanski L. K., MacGregor J. F.: Kinetic studies of cationic photopolymerizations of cycloaliphatic epoxide, triethyleneglycol methyl vinyl ether, and cyclohexene oxide. Polymer Engineering and Science, 45, 1546-1555 (2005) https://doi.org/10.1002/pen.20383 
[32] Builes D. H., Tercjak A., Mondragon I.: Nanostructured unsaturated polyester modified with poly[(ethylene oxide)- $b$-(propylene oxide)- $b$-(ethylene oxide)] triblock copolymer. Polymer, 53, 3669-3676 (2012). https://doi.org/10.1016/j.polymer.2012.06.018

[33] Konuray A. O., Fernández-Francos X., Ramis X.: Latent curing of epoxy-thiol thermosets. Polymer, 116, 191-203 (2017).

https://doi.org/10.1016/j.polymer.2017.03.064
[34] Konuray A. O., Fernández-Francos X., Ramis X.: Curing kinetics and characterization of dual-curable thiolacrylate-epoxy thermosets with latent reactivity. Reactive and Functional Polymers, 122, 60-67 (2018). https://doi.org/10.1016/j.reactfunctpolym.2017.11.010 